\title{
Utilization and Cost of Inpatient Dermatologic Procedures: A Cross-sectional Analysis
}

\author{
Kory P. Schrom ${ }^{1}$, Raghav Tripathi ${ }^{2}$, Harib H. Ezaldein ${ }^{1}$, Jeffrey F. Scott ${ }^{1}$ \\ 1. Dermatology, University Hospitals Cleveland Medical Center, Cleveland, USA 2. Dermatology, Case Western Reserve \\ University, Cleveland, USA
}

$\square$ Corresponding author: Kory P. Schrom, kory.schrom@gmail.com

Disclosures can be found in Additional Information at the end of the article

\begin{abstract}
Knowledge surrounding inpatient dermatologic procedure costs is limited; therefore to learn more, we performed a cross-sectional analysis of dermatologic procedures contained in a publicly available Washington State Comprehensive Hospital Abstract Reporting System database from 2014. Dermatologic procedure utilization and cost were evaluated based on several parameters including demographics, length of hospital stay, payments, and payers. SAS 9.4 was used for the analysis. A total of 14,768 patients underwent dermatologic procedures in 2014 and $81.0 \%$ were white. The average age was 53 years (SD = 0.17 ), and the average payment for all patients who underwent dermatologic procedures was $\$ 85,059.48$ (SD $=\$ 1,284.34)$. The average hospital length of stay was 8.91 days $(\mathrm{SD}=0.07)$. The most common admission type was elective (66.2\%), the most common admit source was a non-healthcare facility point of origin (78.2\%), the most common primary payer was Medicare (36.2\%), and the most common procedure was incision and drainage of skin and subcutaneous tissue (26.5\%), followed by closure of skin and subcutaneous tissue of other sites (20\%). This analysis demonstrated that inpatient dermatologic procedures are a significant driver of inpatient health care costs, and it is critical to determine factors that increase inpatient costs related to dermatologic procedures in order to develop strategies for reducing healthcare costs.
\end{abstract}

Received 03/18/2019

Review began 03/19/2019

Review ended 04/29/2019

Published 05/02/2019

(๑) Copyright 2019

Schrom et al. This is an open access article distributed under the terms of the Creative Commons Attribution License CC-BY 3.0., which permits unrestricted use, distribution, and reproduction in any medium, provided the original author and source are credited.
Categories: Dermatology, Miscellaneous, Epidemiology/Public Health

Keywords: inpatients, outpatients, cost, dermatologic procedures, admissions, payers

\section{Introduction}

Health care spending accounted for $17.9 \%$ of the nation's gross domestic product (GDP) in 2017 , or $\$ 3.5$ trillion [1]. The contribution of inpatient dermatologic procedures to this total is poorly understood. For example, the cost of dermatologic procedures among Medicare beneficiaries was $\$ 2.21$ billion in 2017, with a portion arising from inpatient care [2]. We examined discharge records from community hospital visits to better understand the utilization and cost of non-disease-specific inpatient dermatologic procedures.

\section{Materials And Methods}

We performed a cross-sectional analysis of the Washington State Comprehensive Hospital Abstract Reporting System (CHARS) database to analyze the utilization and cost of inpatient dermatologic procedures performed in 2014 [3]. This database contains record-level data pertaining to inpatient and observation community hospital visits and abstracted information on discharges for civilian hospitals in the state. CHARS database collection methods have been described elsewhere [4]. This study was IRB exempt due to the de-identified and publicly available data.

All patients were adults (>18 years of age) hospitalized in Washington in 2014 who underwent a variety of dermatologic procedure. Descriptive analyses were performed on patient demographics, length of hospital stay, admission type, payment amount, and primary payer. All statistical analyses were performed using SAS 9.4 (Cary, NC).

\section{Results}

A total of 14,768 patients underwent dermatologic procedures in 2014. Descriptive characteristics of the sample are provided in Table 1 . The majority of admissions were elective (66.2\%). The most common primary payer was Medicare (36.2\%) followed by Medicaid (28.5\%). The mean total hospitalization payment for patients undergoing dermatologic procedures was $\$ 85,059.48$, and the average length of hospital stay was 8.9 days. The most common procedure was incision and drainage of skin and subcutaneous (SC) tissue (26.5\%). 


\section{Cureus}

Sample Size, N

Age (years), mean (SD)

Payment (USD), mean (SD)

Length of stay (days), mean (SD)

Sex, N (\%)

Female

Male

Race, N (\%)

Hispanic

White

Black

Other

Admit type, N (\%)

Elective

Emergency

Urgent

Other

Admit source, N (\%)

Non-healthcare facility point of origin

Clinic

Transfer from a hospital (different facility)

Other

Primary payer, N (\%)

Medicare

Medicaid

Health maintenance organization (HMO)

Commercial Insurance

Health Service Contractors

Other

Procedure, N (\%)

Skin \& SC tissue aspiration

Injection or tattooing of skin lesion or defect

Incision \& drainage of skin \& SC tissue

Incision \& removal of foreign body from skin and SC tissue

Incision of skin \& SC tissue

Skin and SC tissue closed biopsy

Skin \& SC tissue diagnostic procedures

Excisional debridement
14,768

$52.6(0.17)$

$\$ 85,059.48(\$ 1,284.34)$

$8.9(0.07)$

$6,560(44.4)$

$8,201(55.6)$

$812(5.5)$

$11,965(81.0)$

$718(4.9)$

$1,273(8.6)$

$9,781(66.2)$

2,071 (14.0)

$2,290(15.5)$

$626(4.2)$

11,547 (78.2)

1,346 (9.1)

1,468 (9.9)

407 (2.8)

5,349 (36.2)

4,205 (28.5)

704 (4.8)

2,575 (17.4)

819 (5.6)

1,116 (7.6)

327 (2.2)

$16(0.1)$

3,891 (26.5)

957 (6.5)

199 (1.4)

539 (3.7)

$2(0.01)$

1,918 (13.7) 


\section{Cureus}

Removal of nail anatomy

Skin chemosurgery

Dermal appendage ligation

Nail anatomy debridement

Non-excisional debridement

Skin \& SC tissue closure
$112(0.8)$

$7(0.1)$

$35(0.2)$

212 (1.4)

$2,265(15.4)$

$2,934(20)$

\section{TABLE 1: Characteristics of patients undergoing an inpatient dermatologic procedure}

$\mathrm{N}$, number; HMO, health maintenance organization; USD, United States dollar; SC, subcutaneous

Characteristics of patients undergoing each of the identified procedures are provided in Table 2. Medicaid was the most common payer when incision and drainage of skin and SC tissue was performed. Skin chemosurgery had the highest average admission cost $(\$ 548,535.70)$ and excisional debridement had the highest aggregate cost $(\$ 5,333,677.80)$.

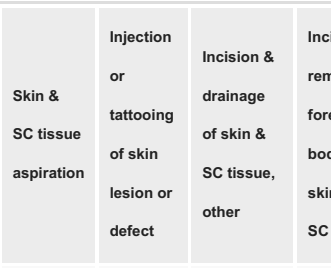

\begin{tabular}{l|l|l}
\begin{tabular}{l|l} 
Incision \& \\
removal of
\end{tabular} & $\begin{array}{l}\text { Incision } \\
\text { of skin \& }\end{array}$ & Skin and \\
\hline foreign & SC tissue \\
\hline body from & tissue, & closed \\
\hline skin and & biopsy \\
SC tissue & other & \\
& &
\end{tabular}
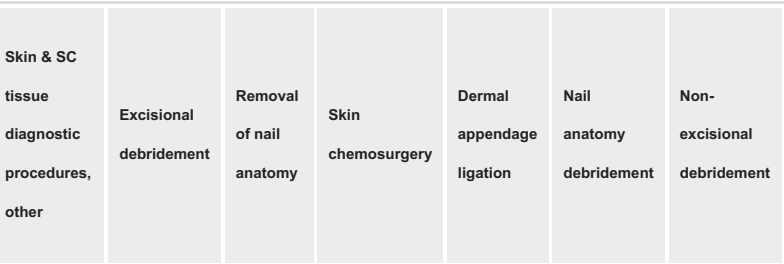

Skin \& SC

issue

closure,

other sites

Total

number of

patients

$327 \quad 16$
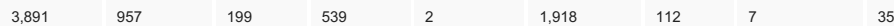

procedure

Age

Mean

$\begin{array}{lll}52.6 & 30.1 \quad 46.8 \\ & \end{array}$

Length

Stayed

(Days)

(USD)

$\begin{array}{lllllllll}\text { Mean } & 73,634.1 & 42,483.6 & 49,238.9 & 122,616.768 & 118,240.1 & 147,213.4 & 68,133.7 & 93,204\end{array}$

$\begin{array}{lllllllll}\text { Min } & 3455 & 10855.9 & 1838 & 1699 & 7942.4 & 4176.3 & 68130.7 & 42883\end{array}$

$\begin{array}{llllllll}\operatorname{Max} & 1,158,397 & 172,812.3 & 2,248,144.1 & 4,586,665.2 & 982,935.6 & 362,0874.3 & 68,136.7\end{array}$

Sex

Female $\quad 159 \quad 15 \quad 1718 \quad 5$

Male

168

$2173 \quad 409$

85

Race

Hispanic

199 


\section{Cureus}

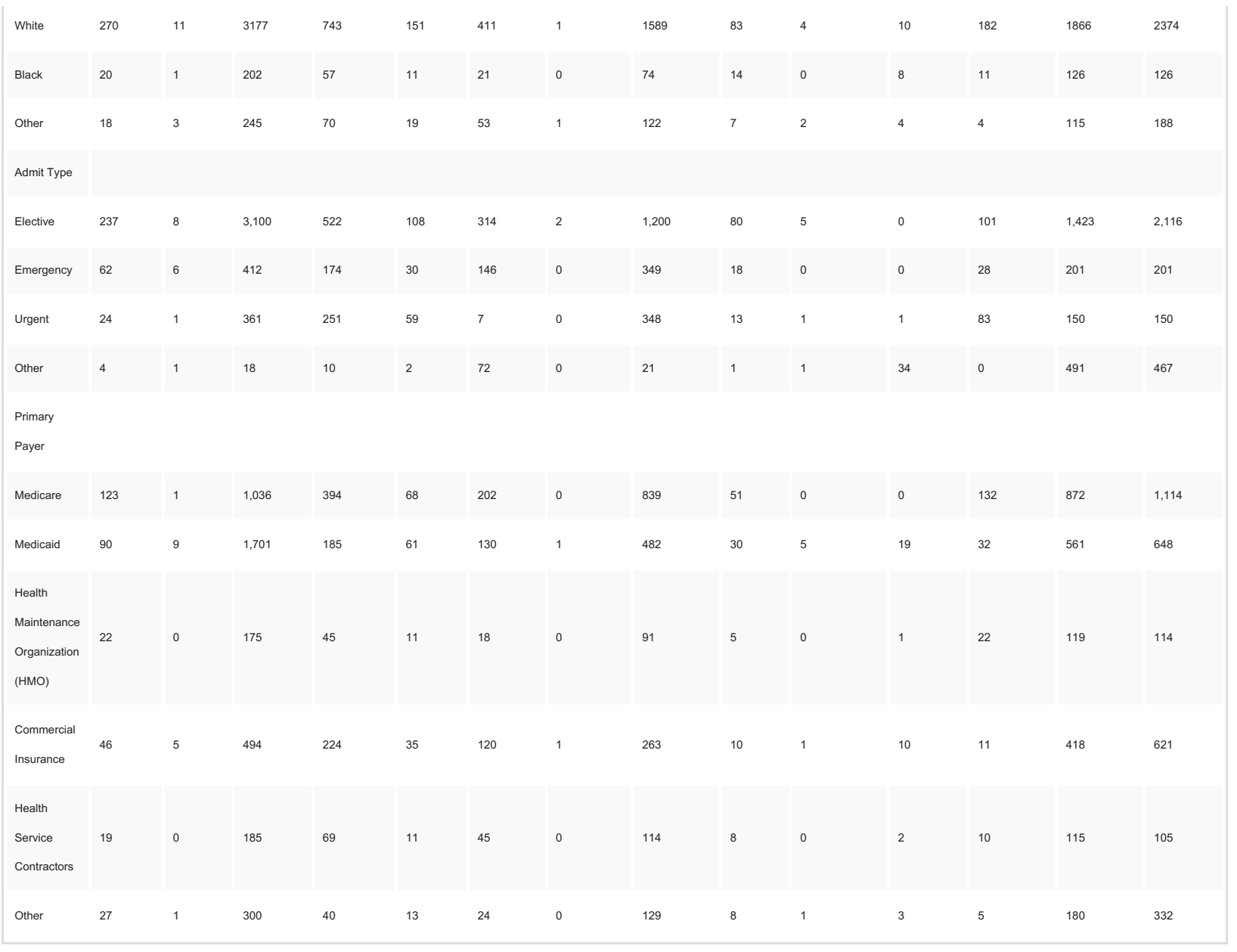

TABLE 2: Characteristics of dermatologic procedures

USD, United States Dollar; SC, subcutaneous

\section{Discussion}

The majority (55.2\%) of financial costs related to dermatologic care, including procedural costs, are experienced in the outpatient setting [5]. While inpatient costs contribute significantly to overall healthcare expenditures (20.1\%), understanding of these costs is limited [1]. Moreover, data related to dermatologic costs in the inpatient setting primarily focus on disease-specific aggregate costs. For example, inpatient costs for care for psoriasis have been shown to be cost-prohibitive when compared to outpatient treatment $(13,042 €$ versus $2,984 €)$, especially when accounting for biologic therapy use [6].

This current analysis is unique in that it identifies dermatologic procedures performed during an inpatient admission independent of dermatologic diagnosis and reveals potential factors that may be used to stratify patients undergoing a dermatologic procedure and suggest opportunities for cost reduction. This study is limited by its regional geographic encashment. Co-morbid diagnoses and direct cost of dermatologic procedures could not be analyzed, and aggregate cost reporting may have overestimated the relative cost contribution. Finally, provider specialty and level of training were not available.

Most patients received a dermatologic procedure during an elective admission and the primary payer was either Medicare or Medicaid. Additionally, our findings support dermatologic consultation when dermatologic procedures are considered. Diagnostic procedures recommended by an appropriately consulted dermatologist yield a definitive diagnosis in up to $80 \%$ of cases. Moreover, $45 \%$ to $80 \%$ of diagnoses will change after dermatology consultation preventing unnecessary therapy and costly hospital stays [7]. Finally, dermatology consultation may also facilitate outpatient follow-up for a procedure rather than performing it during admission.

\section{Conclusions}




\section{Cureus}

Inpatient dermatologic procedures are a significant driver of inpatient health care costs. It is critical to determine factors that increase inpatient costs related to dermatologic procedures to develop strategies for reducing healthcare costs. A good initial cohort for future study would be patients receiving a dermatologic procedure during an elective admission who have Medicare or Medicaid.

\section{Additional Information}

\section{Disclosures}

Human subjects: All authors have confirmed that this study did not involve human participants or tissue. Animal subjects: All authors have confirmed that this study did not involve animal subjects or tissue. Conflicts of interest: In compliance with the ICMJE uniform disclosure form, all authors declare the following: Payment/services info: All authors have declared that no financial support was received from any organization for the submitted work. Financial relationships: All authors have declared that they have no financial relationships at present or within the previous three years with any organizations that might have an interest in the submitted work. Other relationships: All authors have declared that there are no other relationships or activities that could appear to have influenced the submitted work.

\section{References}

1. National Health Expenditure Data: NHE Fact Sheet. (2018). Accessed: January 07, 2019: https://www.cms.gov/Research-Statistics-Data-and-Systems/Statistics-Trends-andReports/NationalHealthExpendData/index....

2. Tan SY, Tsoucas D, Mostaghimi A: Association of dermatologist density with the volume and costs of dermatology procedures among Medicare beneficiaries. JAMA Dermatol. 2018, 154:73-76. 10.1001/jamadermatol.2017.4546

3. Comprehensive Hospital Abstract Reporting System (CHARS). (2014). Accessed: November 14, 2018 : https://www.doh.wa.gov/DataandStatisticalReports/HealthcareinWashington/HospitalandPatientData/HospitalDisch

4. Salvatierra GG, Gulek BG, Erdik B, Bennett D, Daratha KB: In-hospital sepsis mortality rates comparing tertiary and non-tertiary hospitals in Washington state. J Emerg Med. 2018, 54:785-792. 10.1016/j.jemermed.2018.01.027

5. Dehkharghani S, Bible J, Chen JG, Feldman SR, Fleischer AB Jr: The economic burden of skin disease in the United States. J Am Acad Dermatol. 2003, 48:592-599. 10.1067/mjd.2003.178

6. Steinke SI, Peitsch WK, Ludwig A, Goebeler M: Cost-of-illness in psoriasis: comparing inpatient and outpatient therapy. PLoS One. 2013, 8:78152. 10.1371/journal.pone.0078152

7. Biesbroeck LK, Shinohara MM: Inpatient consultative dermatology. Med Clin North Am. 2015, 99:13491364. 10.1016/j.mcna.2015.06.004 